the very considerable mixt ure of blood in the ventricle found by Prakash ${ }^{1}$ in Uromastix hardwicki is not found in Lacerta viridis.

Attention must also be directed to the fact that the results so far obtained tend to support the views of von Hofsten ${ }^{2}$ concerning the nature of the blood conveyed by the left systemic arch in reptiles. Von Hofsten maintains that in Lepidosauria during ventricular systole the free edge of the interventricular septum tends to complete the division of the ventricle in such a way that the opening of the left systemic arch lies alongside that of the right in the cavum arteriosum (left ventricular cavity) and that therefore these two systemic vessels receive blood of the same degree of mixture. But in Chelonia, von Hofsten believes that the opening of the left systemic arch lies to the right of the free edge of the interventricular septum and so during systole will receive blood from the cavum pulmonale. On this latter point we can express no opinion at present; but the results outlined above lead us to believe that in Lacerta viridis there is no marked difference in the type of blood conveyed by left and right systemic arches.

G. E. H. Foxon J. GRIFFITH MYfanwy Price

Department of Biology,

Guy's Hospital Medical School, London, S.E.1. May 11.

1 Prakash, R., Indian J. Radiol., 6, 126 (1952).

von Hofsten, N., Zool. Bidr. Uppsala. 20. 501 (1941).

\section{Intersexuality in Asellus aquaticus L. parasitized by a Larval Acanthocephalan}

InTERSEXes in Asellus aquaticus L., in which the anterior abdominal appendages are intermediate in form between the male and female condition, have been recorded from time to time and their occurrence has been reviewed by Maercks ${ }^{1}$. They were always females, 5-8 mm. in length. Needham ${ }^{2}$ has pointed out that their anterior pleopods, which were never completely male in form, correspond to various stages in the normal development of the male organs.

Collections of $A$. aquaticus from two sources in Perthshire have yielded 80 individuals, approximately 1.5 per cent of the total collections, parasitized by a larval polymorphid. Of these parasitized individuals, 39 appeared to be normal males of 3-8 $\mathrm{mm}$. and 13 normal females of $3 \cdot 25-7 \mathrm{~mm}$. The remainder, 28 individuals of 5-8.5 mm., showed various degrees of intersexuality. More than 90 per cent of those parasitized were noticeably darker than normal.

All the females and the intersexes had unexpanded oostegites typical of the immature or non-breeding female. The second pleopods of the intersexes were at different stages of development similar to those described by Needham ${ }^{3}$ in the normal development of the male. In those individuals in which the development of the second pleopods was well advanced, first pleopods of male form were present. Where both first and second pleopods were almost completely male, copulatory styles were sometimes present. In some cases, development of the second pleopods was more advanced on one side than on the other.

Like those described by Maercks ${ }^{1}$, these intersexes would seem to be modified females, since it is possible to arrange them in such a way that their anterior pleopods present a series similar to that seen in the normal development of the male. Further, three females and one intersex showed a change in a male direction after being brought into the laboratory. Two of these females developed first pleopods while under observation, confirming Needham's ${ }^{3}$ assertion, on embryological grounds, that it is the first pair of pleopods which is absent in female Asellus.

These intersexes differed from those described by Maercks ${ }^{1}$ in that copulatory styles were never present unless both first and second pleopods were almost completely male, whereas in his specimens copulat ory stylés were always present although the first pleopods might be absent and the second only slightly male. Unlike his intersexes, they have not been found carrying eggs or with expanded oostegites although collected together with many breeding females.

The fact that all the parasitized females and intersexes had immature oostegites is similar to the observations of Le Roux ${ }^{4}$ on the state of oostegites in Gammarus pulex (L.) parasitized by the larvæ of the acanthocephalan Polymorphus minutus (Goeze). It has been shown experimentally by $L e R_{0 u x^{5}}$ for Gammarus and by Haemmerli-Boveri ${ }^{6}$ for Asellus that the development of the oostegites is correlated with ovarian activity.

Although in the present instance no intersexes have been found among more than 3,500 unparasitized Asellus, it is not suggested here that intersexuality only occurs in parasitized individuals. Maercks ${ }^{1}$ sectioned his specimens so that any parasites present would have been seen.

It is hoped to carry out further work on the relationship between intersexuality and parasitization in Asellus.

Brown Trout Research Laboratory,

W. R. MUnRo

Faskally House,

Pitlochry, Perthshire.

March 20.

${ }^{1}$ Maercks, H. H., Zool. Jahrb., Abt. f. Zool., 48, 434 (1931).

${ }^{2}$ Needham, A. E., Quart. J. Micr. Sci., 82,61 (1941).

s Needham, A. E., Quart. J. Micr. Sci., 81, 127 (1928).

- Ie Roux, M.-I., C.R. Acad. Sci., Paris, 192, 889 (1931).

'Le Roux, M.-L., C.R. Acad. Sci., Paris, 193, 885 (1931).

- Haemmerli-Boveri, V., Zool. Vergl. Physiol., 4, 668 (1926) (seen only in abstract).

\section{Distribution of Copper Fungicide Deposits on Plant Surfaces}

Is work on spray application problems, a simple method has been devised, capable of use in the field, by which the pattern of copper fungicide deposits on treated plant surfaces may be assessed and permanently recorded. Earlier methods using paper impregnated with a suitable detecting agent are not entirely satisfactory, since deposits accumulating in depressions may not be picked up. This has been overcome by preparing an impression of the treated surface in plaster-of-Paris.

The plant surface holding the deposit is gently pressed into the calcium sulphate cream, taking eare to avoid the occlusion of air. The plaster is allowed to harden for some twenty minutes, and the plant material is then carefully peeled off. The plaque, which retains the deposit, is then wetted with a 0.2 per cent aqueous solution of sodium diethyldithiocarbamate, when the imprint of the distribution of the fungicide develops. An approximate quantita- 